\title{
Designing Anti-Zika Virus Peptides Derived from Predicted Human-Zika Virus Protein-Protein Interactions
}

2 Tom Kazmirchuk $^{1}$, Kevin Dick ${ }^{2}$, Daniel. J. Burnside ${ }^{1}$, Brad Barnes ${ }^{2}$, Houman Moteshareie $^{1}$, Maryam Hajikarimlou ${ }^{1}$, 3 Katayoun Omidi ${ }^{1}$, Duale Ahmed ${ }^{1,3}$, Andrew Low ${ }^{1}$, Clara Lettl ${ }^{1}$, Mohsen Hooshyar ${ }^{1}$, Andrew Schoenrock ${ }^{4}$, Sylvain $4 \mathrm{Pitre}^{4}$, Mohan Babu ${ }^{5}$,Edana $\mathrm{Cassol}^{3}$, Bahram Samanfar ${ }^{6}$, Alex Wong ${ }^{1}$, Frank Dehne ${ }^{3}$, James. R. Green ${ }^{2}$, and Ashkan Golshani $^{1^{*}}$

$6 \quad{ }^{1}$ Department of Biology and Institute of Biochemistry, and Ottawa Institute of Systems Biology, Carleton

7 University, Ottawa, Ontario. K1S 5B6

$8 \quad{ }^{2}$ Department of Systems and Computer Engineering, Carleton University, Ottawa, Ontario. K1S 5B6

$9 \quad{ }^{3}$ Department of Health Science, Carleton University, Ottawa, Ontario. K1S 5B6

$10 \quad{ }^{4}$ School of Computer Science, Carleton University, Ottawa, Ontario. K1S 5B6

$11{ }^{5}$ Department of Biochemistry, University of Regina, Regina, Saskatchewan S4S 0A2

$12{ }^{6}$ Agriculture and Agri-Food Canada, Ottawa Research and Development Centre (ORDC), Ottawa, Ontario. K1A

$13 \quad 0 \mathrm{C} 6$

$14 *$ Corresponding Author:

15 Email: ashkan_golshani@carleton.ca

16

17

25 Keywords: Synthetic peptide design; anti-Zika virus peptides; In silico drug design; protein-protein interaction prediction; host-virus interactions

\section{Acknowledgments}

28 This work was funded by the Natural Sciences and Engineering Research Council of Canada (NSERC). The authors claim no conflict of interest. 


\section{Abstract}

31 The production of anti-Zika virus (ZIKV) therapeutics has become increasingly important as the propagation of the 32 devastating virus continues largely unchecked. Notably, a causal relationship between ZIKV infection and 33 neurodevelopmental abnormalities has been widely reported, yet a specific mechanism underlying impaired neurological development has not been identified. Here, we report on the design of several synthetic competitive inhibitory peptides against key pathogenic ZIKV proteins through the prediction of protein-protein interactions (PPIs). Often, PPIs between host and viral proteins are crucial for infection and pathogenesis, making them attractive targets for therapeutics. Using two complementary sequence-based PPI prediction tools, we first produced a comprehensive map of predicted human-ZIKV PPIs (involving 209 human protein candidates). We then designed several peptides intended to disrupt the corresponding host-pathogen interactions thereby acting as anti-ZIKV therapeutics. The data generated in this study constitute a foundational resource to aid in the multi-disciplinary effort to combat ZIKV infection, including the design of additional synthetic proteins.

\section{Introduction}

43 The Zika virus (ZIKV) is currently causing an ongoing pandemic, incurring considerable human impact. The rapid 44 spread of the virus throughout the Western hemisphere has driven a significant accumulation of knowledge on ZIKV infection [1-4]. The ZIKV is a positive-sense single stranded RNA (+ssRNA) arbovirus from the genus Flavivirus [5,6]. A mature ZIKV virion contains a monopartite segment of +ssRNA 10,800 nucleotides enclosed in a capsid

47 comprised of C-proteins and surrounded by a $50 \mathrm{~nm}$ spherical envelope. The membrane is comprised of membrane

48 (M) and envelope (E) proteins arranged around the icosahedral capsid. The entire genome is translated in to a single

49 polyprotein 3,419 amino acids in length, which is cleaved at ten locations to produce 11 individual proteins. Despite

50 significant similarity to other Flaviviridae, the ZIKV results in some symptoms that are not associated with members

51 of this viral family such as Dengue or Yellow Fever [7].

52 Host-virus protein-protein interactions (PPIs) are essential for viral infection and propagation as well as neuroinvasion

53 [8]. The ZIKV appears to be highly neuroinvasive $\left(6.5 \times 10^{7}\right.$ viral RNA copies/mg of brain tissue [9]) and has been

54 linked to numerous neurological complications including congenital brain abnormalities [10], infant microcephaly

55 [11], Guillain-Barré syndrome [12], and meningoencephalitis [13]. Additionally, the ZIKV has been found to cause

56 testicular atrophy [14], and may be spread as a sexually transmitted infection [15]. 
57 Investigating the host-virus interactome is an important step in identifying targets for novel anti-viral therapeutics

58 [16]. Designing molecules, such as competitive peptides that interfere with these PPIs, can serve as efficient anti-viral

59 therapies [17-19]. An early example of such anti-viral peptides is S6 - a 111 amino acid long fragment of human

60 integrase interactor protein 1 which forms a PPI with HIV-1 integrase protein. S6 is shown to be an effective inhibitor

61 of HIV-1 replication [20].

62 Global PPI prediction analysis is a robust method for probing the network of host-pathogen interactions that occur at

63 various stages of the viral life cycle. Recognition of pertinent PPIs between host cell proteins and ZIKV components

64 can guide the development of synthetic inhibitory peptides capable of disrupting such interactions. In the current study, we use this approach to generate a list of specific peptide sequences that might function in combating ZIKV infection.

66 We believe that the overproduction of these synthetic peptides may interfere with several human-ZIKV PPIs, thus

67 interrupting the ZIKV lifecycle. Considering that the World Health Organization has lifted the declaration of emergency for the ZIKV, shifting to threat management of the ZIKV is important as many mechanisms of

69 pathogenesis are still unclear. The designed peptides provided here may therefore prove to be useful therapeutics

70 against ZIKV infection, and could aid in overall ZIKV management.

\section{Materials and Methods}

\section{PIPE Prediction}

73 From the suite of available sequence-based methods, the Protein-Protein Interaction Prediction Engine (PIPE) excels

74 in terms of specificity and execution time [21]. PIPE was developed to investigate short co-occurring polypeptide

75 sequences between two proteins to determine their likelihood of interaction [22-24]. This likelihood of interaction is

76 captured by two scores: PIPE-Score and Similarity-Weighted score (further described in Pitre et al, 2008) [24]. Two

77 datasets were used to perform the PIPE analysis, the first using the entire set of known human-virus interactions

78 (irrespective of virus type) and the second considering only interactions specific to the Flaviviridae, Herpeviridae,

79 Arteriviridae, and Coronaviridae families. PIPE analysis was applied to all combinations of human-ZIKV (20,515

80 human proteins, $11 \mathrm{ZIKV}$ proteins). This resulted in a high confidence interaction network comprising the top-scoring

$810.02 \%$ of predicted PPIs including 45 human-ZIKV interactions corresponding to 23 unique human proteins. From

82 these 23 candidates, we chose the top 17 to further investigate based on their apparent relevance to human health.

\section{DeNovo Prediction}


84 DeNovo is a host-virus PPI prediction tool tailored to predict cross-species protein interactions for newly identified viral organisms for which no interaction data are previously known [25]. Given the lack of known interactions for the ZIKV, DeNovo is well suited to this task. Similar to PIPE, DeNovo is a sequence-based method designed to leverage all currently known viral interaction data [25]. Unlike PIPE, however, DeNovo exploits the physiochemical properties of the human host's proteins to inform its predictions [25]. Learning these characteristics in the commonly shared human host, across all known host-viral interactions, enhances the discovery of interactions in the organism of interest. Determining the high confidence interactions as those with a probability of interaction greater than or equal to $80 \%$ resulted in 871 human-ZIKV interactions ( $0.38 \%$ of all putative PPIs) corresponding to 186 candidate human proteins (supplementary table 1). From these 186 candidates, we performed a literature search on eight due to their relevance to ZIKV infection to supplement the 17 from the PIPE analysis.

\section{Prediction of PPI-Sites}

The list of PPIs generated from both methods can be used to inform the design of anti-ZIKV therapeutics by using peptide sequences from the predicted PPI site, which we refer to as the PPI-Site. We define the PPI-Site as the peptide sequence that is responsible for mediating the PPIs. When PIPE predicts an interaction between the two corresponding proteins, it will also report the predicted site of interaction using the amino acid sequences from both proteins. Using our previously reported PIPE output, we selected for PIPE's built-in peak height attribute, which we refer to as H. This is a measure of the number of times two corresponding sequence pairs co-occur within the annotated database of known PPI normalized to its expected occurrence. Selecting for $\mathrm{H}$ within our top 17 interactions produced 4 humanZIKV PPI-Sites which we believe mediate the human-ZIKV PPIs.

\section{Results}

To generate a list of anti-ZIKV peptides, we first predicted a network of PPIs between humans and the ZIKV. This was accomplished using two complementary computational modeling methods - each trained on currently known high-confidence human-viral interactions obtained from VirusMentha (incorporating the MINT, IntAct, DIP, MatrixDB, and BioGRID databases) [26]. The first method, PIPE, is proficient in host-virus interaction prediction and has successfully been used to predict novel interactions in humans, yeast, and most recently in viruses (Hepatitis C and HIV-1) $[22,24,27,28]$. The second method, DeNovo, is specifically designed for the prediction of interactions between proteins from a host and newly discovered viral organisms independent of prior known host-virus interactions [25]. Figure 1 highlights the ontology classification of the 209 human proteins believed to participate in human-ZIKV 
112 PPIs based on their interaction profiles from both methods. In table 1, we report a total of 25 high priority human

113 protein (and their associated ZIKV interactors) from our list of 209 candidates based on their correlation to known

114 mechanisms of ZIKV infection, pathology, and symptomology. Of the eleven ZIKV proteins considered, the nine

115 interacting proteins reported in our results correspond to the structural proteins: Envelope (E), Capsid (C),

116 Premembrane (Pr), and Membrane (M), and the non-structural proteins: NS1, NS2A, NS3, NS4B, and the RNA-

117 dependent RNA polymerase NS5 proteins. These proteins not only highlight protein candidates for PPI-based

118 therapeutic design, but also they may provide potential mechanisms of ZIKV infection.

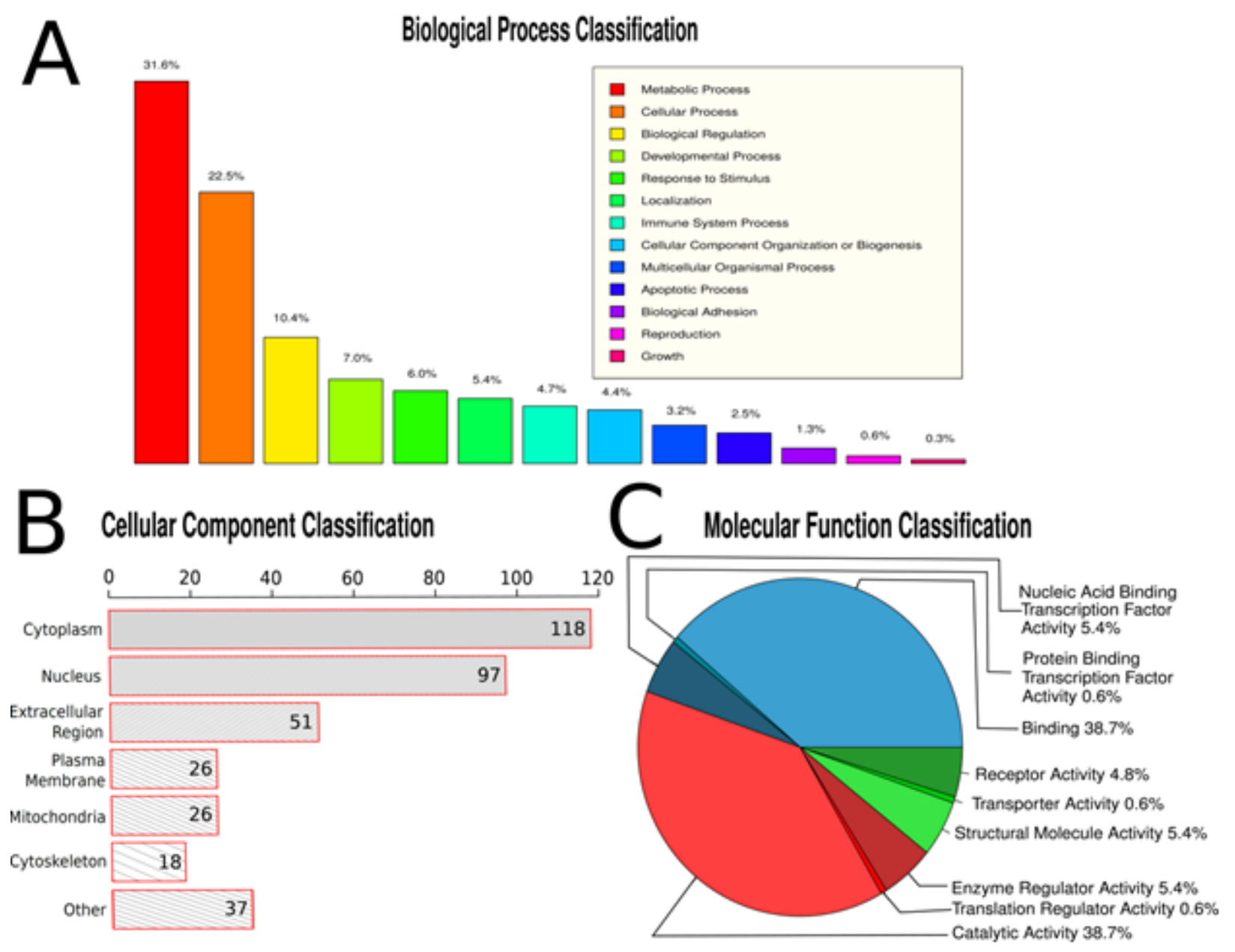

Fig. 1 Human Protein Geneontology (GO) Classification using PANTHER GO-Slim. The evaluation of GO term

121 enrichment for 198 of the 209 high confidence human proteins ( 8 unmapped proteins were excluded) for biological

122 process (a), cellular component (b) and molecular function (c). Our list of 209 predicted high confidence human

123 proteins can be found in supplementary table 1 

interactors, function (F), associated disease phenotype (D), and supporting literature.

\begin{tabular}{|c|c|c|c|}
\hline $\begin{array}{c}\text { Human } \\
\text { Proteins }\end{array}$ & ZIKV Proteins & Function or Disease Phenotype & Reference \\
\hline ENO1 (P) & NS5, NS3, NS1*, M* & Affects cell proliferation, differentiation $(\mathrm{F})$ & [29-31] \\
\hline ENO2 $(\mathrm{P})$ & $\mathrm{NS} 5, \mathrm{NS} 3, \mathrm{NS} 1^{*}, \mathrm{M}^{*}$ & Affects cell proliferation, differentiation $(\mathrm{F})$ & [29-31] \\
\hline ENO3 (P) & $\mathrm{NS} 3, \mathrm{NS} 1 *, \mathrm{E}^{*}$ & $\beta$-enolase deficiency (D) & {$[32]$} \\
\hline RNASET2 (P) & $\mathrm{NS} 3 *$ & Microcephaly (D) & [33-36] \\
\hline CALR3 (N) & NS4B, M & Male fertility, spermatogenesis, gamete fusion $(\mathrm{F})$ & [37-39] \\
\hline NME1 (P) & NS3 & Induction of fibronectin $(\mathrm{F})$ & [40] \\
\hline NME3 (P) & NS5, NS3, M & Cell motility in somatic cells, spermatozoa (D) & [41] \\
\hline RNF151 (N) & $\operatorname{Pr}, \mathrm{M}$ & Spermatogenesis $(\mathrm{F})$ & [42] \\
\hline RNF125 (P) & NS3 & Regulation of HIV-1 replication (F) & [43] \\
\hline FUNDC1 (P) & NS3 & Activates hypoxia-induced mitophagy $(\mathrm{F})$ & [44] \\
\hline BCLG (P) & NS5, NS3, M & Apoptosis factor $(\mathrm{F})$ & [45] \\
\hline TRAF4 (P) & NS5, NS3, M* & Impaired neural crest development, folding (D) & [46] \\
\hline MLPH (P) & NS3 & Griscelli syndrome (D) & [47] \\
\hline PIAS3 (P) & NS3 & SUMOylation of photoreceptors (F) & {$[48]$} \\
\hline CAMTA2 (P) & $\mathrm{NS} 5, \mathrm{NS} 3, \mathrm{M}^{*}, \mathrm{C}^{*}$ & Decreased cardiac growth (D) & {$[49]$} \\
\hline $\mathrm{AZI} 2(\mathrm{P})$ & NS5, NS3, M* & Neurodevelopment (D) & {$[50]$} \\
\hline MATR3 (P) & NS3 & Cardiac development $(\mathrm{F})$ & [51] \\
\hline CEP63 (P) & NS5, NS3 & p53-dependent microcephaly (D) & {$[52]$} \\
\hline RIAM (P) & NS5, NS3 & Leukocyte adhesion deficiency (D) & {$[53]$} \\
\hline DYX1C1 (N) & NS4B, M & Dyslexia (D) & {$[54]$} \\
\hline SNAP25 (N) & NS4B, M & Huntington's Disease (D) & [55] \\
\hline YWHAE (N) & NS4B & Neurocognitive, Cerebrospinal fluid marker (D) & {$[56]$} \\
\hline $\operatorname{COX} 17(\mathrm{~N})$ & NS4B, NS2A & Cardiomyopathy, hepatic failure (D) & [57] \\
\hline SPZ1 (N) & NS4B, M & Spermatogenesis $(\mathrm{F})$ & [58] \\
\hline DNAJA1 (N) & $\operatorname{Pr}, \mathrm{M}$ & Testis development, spermatogenesis $(\mathrm{F})$ & [59] \\
\hline
\end{tabular}

* indicates interaction pairs also predicted for the Dengue virus. 
127 From the list of 25 candidates, we here examine a subset of four proteins - RNASET2, ENO2, TRAF4, and CEP63 of

128 particular interest for anti-ZIKV therapeutics. The first candidate, RNASET2, has been implicated in the occurrence

129 of microcephaly [33] which is of special interest as no proposed mechanism exists linking the ZIKV to microcephaly.

130 The second candidate, ENO2, has been linked to early brain development of humans [60], and may be useful in the

131 study the pathogenesis of possible ZIKV-associated neurological disorders. TRAF4 is our third candidate and has

132 been reported to be involved in TNF-receptor activity [46]. We believe that interfering with this receptor may affect

133 ZIKV absorption and/or release. Finally, CEP63 has been previously implicated in p53 dependent microcephaly [52].

134 Considering that microcephaly is a hallmark of ZIKV infection in infants [61], designing a therapeutic which interrupts

135 a ZIKV interaction with CEP63 may prove useful. We identified the site of interactions (PPI-Site) between these

136 proteins and their ZIKV interacting partners (table 2). Overproduction of these PPI-Sites via synthetic peptides can

137 interfere with human-ZIKV PPIs, potentially acting as competitive inhibitors against the corresponding ZIKV protein.

138 Consequently, PPI-Sites can provide the basis for effective anti-ZIKV therapeutics.

139

140

141

142

143

144

145

146

147

148

149

150

151 
Table 2: The amino acid sequence for Human-ZIKV PPIs. The peptides believed to mediate the interactions are indicated. P1-P4 represent peptides that may function as antiZIKV therapeutics. These peptides may interact with the corresponding ZIKV proteins and prevent them from interacting with their human PPI partners.

Human Protein

ZIKV Protein

\begin{abstract}
PPI-Site;
Human
\end{abstract}

PPI-Site; ZIKV

$\begin{array}{ll}\text { P1 } & (90-178) \\ (188-215) & \text { DGLSEVQLLA } \\ \text { SQDEEVQTIGIEL } & \text { VPPGERARNI } \\ \text { CLTKQDQQLQN } & \text { QTLPGIFKTK } \\ \text { CTEP } & \text { DGDIGAVALD } \\ & \text { YPAGTSGSPI } \\ & \text { LDKCGRVIGL } \\ & \text { YGNGVVIKNG } \\ & \text { SYVSAITQGK } \\ & \text { REEETPVEC }\end{array}$

P2

(76-105)

ALISSGLSVV

EQEKLDNLML

ELDGTENKSK

(0-248)
GGGTGETLGEKWKA RLNQMSALEFYSYKK SGITEVCREEARRAL KDGVATGGHAVSRGS AKIRWLEERGYLQPYG KVVDLGCGRGGWSYY AATIRKVQEVRGYTKG GPGHEEPMLVQSYGWN IVRLKSGVDVFHMAAE PCDTLLCDIGESSSSPEV EETRTLRVLSMVGDWLE KRPGAFCIKVLCPYTST MMETMERLQRRHGGGL VRVPLCRNSTHEMYWV SGAKSNIIKSVSTTSQLL LGRMDGPR

$\begin{array}{ll}\text { P3 } & (11-57) \\ (453-482) & \text { RKLQTRSQT } \\ \text { MCALVSRQRQ } & \text { WLESREYTK } \\ \text { ELQELRRELE } & \text { HLIKVENWIF } \\ \text { ELSVGSDGVL } & \text { RNPGFALVAV }\end{array}$
AIAWLLGSST

\begin{abstract}
TRAF4
MPGFDYKFLEKPKRRLLCPLCGKPMREPVQVSTCGHRFCD TCLQEFLSEGVFKCPEDQLPLDYAKIYPDPELEVQVLGLPIR CIHSEEGCRWSGPLRHLQGHLNTCSFNVIPCPNRCPMKLSR RDLPAHLQHDCPKRRLKCEFCGCDFSGEAYESHEGMCPQE SVYCENKCGARMMRRLLAQHATSECPKRTQPCTYCTKEFV FDTIQSHQYQCPRLPVACPNQCGVGTVAREDLPGHLKDSCN TALVLCPFKDSGCKHRCPKLAMARHVEESVKPHLAMMCAL VSRQRQELQELRRELEELSVGSDGVLIWKIGSYGRRLQEAKA KPNLECFSPAFYTHKYGYKLQVSAFLNGNGSGEGTHLSLYIR VLPGAFDNLLEWPFARRVTFSLLDQSDPGLAKPQHVTETFHP DPNWKNFQKPGTWRGSLDESSLGFGYPKFISHQDIRKRNYVR DDAVFIRAAVELPRKILS
\end{abstract}

\begin{abstract}
Membrane
\end{abstract}
AVTLPSHSTRKLQTRSQTWLESREYTKHLIKVENWIFR NPGFALVAVAIAWLLGSSTSQKVIYLVMILLI APAYS

\section{CEP63}

MEALLEGIQNRGHGGGFLTSCEAELQELMKQIDIMVAHKKS EWEGRTHALETCLKIREQELKSLRSQLDVTHKEVGMLHQQV EEHEKIKQEMTMEYKQELKKLHEELCILKRSYEKLQKKQMR EFRGNTKNHREDRSEIERLTAKIEEFRQKSLDWEKQRLIYQQ QVSSLEAQRKALAEQSEIIQAQLVNRKQKLESVELSSQSEIQH LSSKLERANDTICANELEIERLTMRVNDLVGTSMTVLQEQQQ KEEKLRESEKLLEALQEEKRELKAALQSQENLIHEARIQKEK LQEKVKATNTQHAVEAIRPREESLAEKKYTSQGQGDLDSVL SQLNFTHTSEDLLQAEVTCLEGSLESVSATCKQLSQELMEKY EELKRMEAHNNEYKAEIKKLKEQILQGEQSYSSALEGMKME

\section{NS3}

SGALWDVPAPKEVKKGETTDGVYRVMTRRLLGSTQ VGVGVMQEGVFHTMWHVTKGAALRSGEGRLDPYW GDVKQDLVSYCGPWKLDAAWDGLSEVQLLAVPPGE RARNIQTLPGIFKTKDGDIGAVALDYPAGTSGSPILDK CGRVIGLYGNGVVIKNGSYVSAITQGKREEETPVECF LRTVILAPTRVVAAEMEEALRGLPVRYMTTAVNVTH SGTEIVDLMCHATFTSRLLQPIRVPNYNLNIMDEAHFT DPSSIAARGYISTRVEMGEAAAIFMTATPPGTRDAFPD SNSPIMDTEVEVPERAWSSGFDWVTDHSGKTVWFVPS EPSMLKKKQLTVLDLHPGAGKTRRVLPEIVREAIKKR

$\begin{array}{ll}\text { P4 } & (90-178) \\ (246-285) & \text { DGLSEVQLLAVPPG } \\ \text { QEQQQKEEKL } & \text { ERARNIQTLPGIFKT } \\ \text { RESEKLLEAL } & \text { KDGDIGAVALDYPA } \\ \text { QEEKRELKA } & \text { GTSGSPILDKCGRVI } \\ \text { ALQSQENLIHE } & \text { GLYGNGVVIKNGSY } \\ & \text { VSAITQGKREEETPV } \\ & \text { EC }\end{array}$




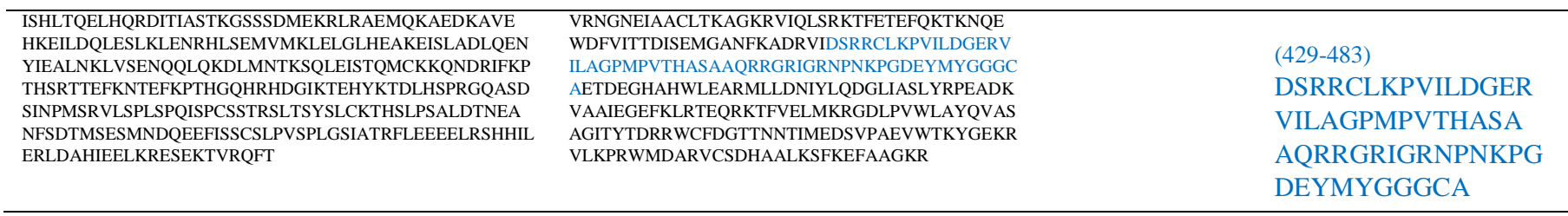

\section{Discussion}

157 At the outset of this study, we sought to design anti-ZIKV therapeutics by identifying PPI-Sites from predicted human-

158 ZIKV PPIs. By identifying these PPI-Sites on both the host and viral proteins, we provide a scaffold for the design of peptides which may inhibit ZIKV proteins or compete for binding to functionally-relevant targets. We employed two computational tools to predict PPIs, namely PIPE and DeNovo, and produced a priority list of testable protein interaction candidates which can be used as an important resource for multiple disciplines. In particular, the amino acid sequences identified here as being responsible for mediating interactions between human and ZIKV proteins can serve as the basis for engineering additional anti-ZIKV therapeutics.

One of the primary public health concerns of the ZIKV infection has been occurrence of microcephaly in newborn children who are infected with the virus, or whose mothers have been infected. It is therefore possible that the virus is acting on the fetus during pregnancy, and affecting development. Our candidate, RNASET2 has been causally linked to a range of neurologic impairments including microcephaly, multifocal white matter lesions, and anterior temporal lobe subcortical cysts [33]. RNASET2 has been shown to localize to the lysosome, where it may function in RNA catabolism [62]. Zebrafish models have established that the loss of function in RNASET2 results in neuronal 171 lysosomal disorder [63] congruent with findings in humans that have linked lysosomal disorders to the development 172 of microcephaly [34]. Moreover, a loss of function mutation at amino acid 184 in the RNASET2 protein has been 173 found in infants with cystic leukoencephalopathy leading to microcephaly, white matter lesions, and other temporal 174 lobe deficiencies [33].

175 We predicted an interaction between the human protein RNASET2 and the ZIKV serine protease NS3. Interestingly, 176 two Flaviviridae (Hepatitis C and Dengue) have been found to interact with human RNASET2 protein via their NS3 177 protein in vitro [64]. The proteolytic domain of the ZIKV NS3 serine protease occurs at residues 1-175 [65,66], and 
179 domain [67]. Within this functional domain exists a serine at residue 188, congruent with our predicted site of 180 interaction (PPI-Site, residue 188-215) and four residues downstream of the leukoencephalopathy-associated 181 mutation. Interestingly, we predict that this site interacts with the proteolytic domain of NS3 (PPI-Site, residue 1-178) 182 which may impact the functionality of RNASET2, as the functional domain would theoretically be cleaved in two 183 (Figure 2). Disrupting this interaction via introduction of the identified PPI-Sites (P1) in excess could disrupt the ZIKV 184 lifecycle in the cell. Alternatively, the binding of the PPI-Site to the proteolytic domain of NS3 can interfere with the 185 mode of action of NS3 by deactivating its proteolytic domain in a PPI independent manner. In both cases, excess of 186 P1 may interfere with ZIKV infection and hence may function as an effective anti-ZIKV therapy. 


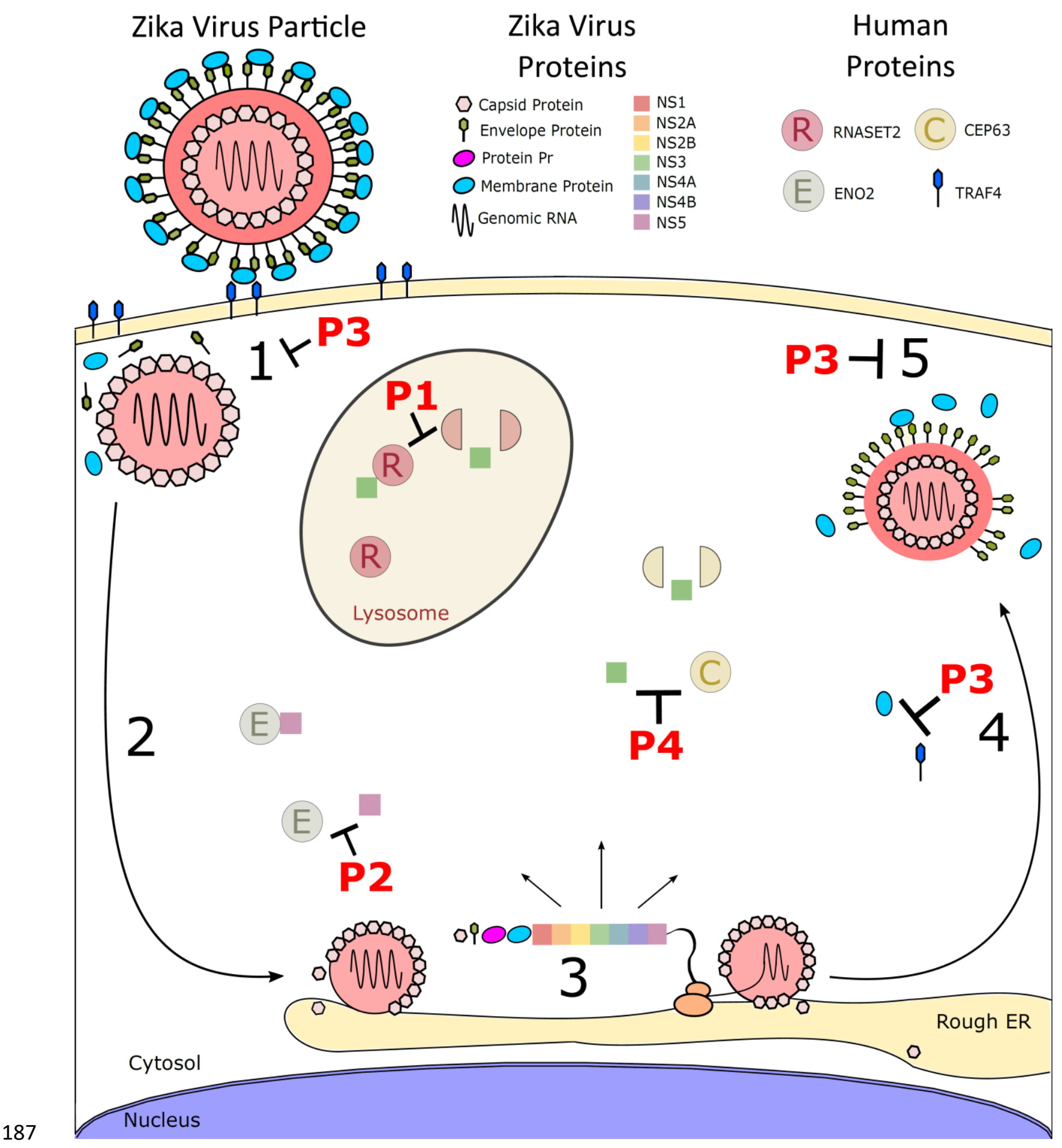

Fig. 2 The ZIKV lifecycle within a human cell, and the peptide drugs that may interfere with its different steps. 1: The ZIKV particle adsorbs into the human cell, possibly via TRAF4. P3 may interfere with this step. 2: The virion is uncoated in the cytoplasm. 3: ZIKV RNA undergoes translation to produce the ZIKV polypeptide. P1, P2 and P4 are designed to interfere with the activity of synthesized ZIKV polypeptides. 4: The immature virion is assembled and 
moves to the cell membrane. 5: The ZIKV particle exits the host cell. P3 may also interfere with these last two steps. The ENO2 interaction with NS5 may impact neurodevelopment. This is the proposed site of P2 activity. The predicted interaction between RNASET2 and NS3, which we hypothesize to cleave the RNASET2 functional protein at amino acid 188 is the predicted site of P1 activity. The interaction between CEP63 and NS3 may result in a cleaved CEP63 protein representing the proposed site of P4 activity. P1: SQDEEVQTIGIELCLTKQDQQLQNCTEP, P2: ALISSGLSVVEQEKLDNLMLELDGTENKSK，P3: MCALVSRQRQELQELRRELEELSVGSDGVL，and P4:

Our additional peptide sequences come from the interactions between ENO2-NS5, TRAF4-M, and CEP63-NS3, as seen in Figure 2. These three additional human protein candidates are all involved in neurodevelopment. Specifically, ENO2 (neuron-specific enolase) is important for normal brain development in humans [30]. A member of the enolase family, ENO2 promotes cell maturation in the central nervous system [68]. During early development, neuronal cells switch from ENO1 (non-neuronal enolase) to ENO2 in order to promote brain development [29] (Figure 2). Interestingly, a similar interaction was reported by Munoz et al. where they describe an interaction between the Aedes aegypti enolase and Dengue virus NS5 protein [69]. The predicted P2 peptide could potentially act as competitive inhibitor for the NS5 binding site. In this way, we predict that P2 will interrupt the lifecycle of the ZIKV in the human cell, thus acting as an effective therapeutic.

209 A previous study identified AXL as a receptor candidate that is active in the ZIKV lifecycle [70]. Although not a 210 receptor, TRAF4 is an essential element for normal TNF receptor function as TRAFs have been previously identified 211 as adaptor proteins for membrane receptors [71]. Therefore, it is possible that the ZIKV M protein may be impacting 212 functionality of the TNF receptor via TRAF4, possibly increasing the function of TNF. Pertaining to 213 neurodevelopment, it has been shown that TRAF4 is required for normal neural crest formation [46]. If the ZIKV M 214 protein is binding to TRAF4 in a inhibitory manner, it is possible that TNF receptor functionality may be impacted 215 [71], and that neural crest formation may be negatively affected [46]. The corresponding PPI-Site derived peptide for 216 this interaction is P3. Overproducing this peptide may interfere with ZIKV adsorption/penetration and thus act as a 217 promising anti-ZIKV therapeutic. As well, if the ZIKV M protein is inhibiting TRAF4 leading to impaired neural crest formation, inhibiting the M protein via P3 would be ideal. 
Finally, a short motif within centrosomal protein CEP63 was predicted to interact with the ZIKV serine protease NS3. This is an important interaction as the loss of CEP63 in mice results in microcephaly [52]. It is therefore possible that the NS3 serine protease could act on one of the two serines within the interaction site on CEP63, rendering the protein dysfunctional. Overproduction of P4 may be able to saturate NS3 activity and prevent detrimental proteolytic cleavage of the endogenous target.

224 In this study, we have identified proteins and PPI-Sites of interest and designed a series of peptides that could be used 225 to combat ZIKV infection. These peptides theoretically interfere with the activity of their corresponding ZIKV proteins by competing for their interacting partners. Additional manipulation and/or modification of the peptides designed in this study can lead to new anti-viral therapeutics with improved properties such as increased half-life or the ZIKV, a process that has been achieved with other viruses and is proposed for the ZIKV [72,73].

\section{References}

231 [1] D.I. Thomas, T.M. Sharp, J. Torres, P.A. Armstrong, J. Munoz-Jordan, K.R. Ryff, A. Martinez-Quinones, J. Arias-Berrios, M. Mayshack, G.J. Garayalde, S. Saavedra, C.A. Luciano, M. Valencia-Prado, S. Waterman, B. Rivera-Garcia, Local Transmission of Zika Virus — Puerto Rico , November 23, 2015 - January 28, 2016,

[2] A.S. Fauci, D.M. Morens, Zika Virus in the Americas - Yet Anoter Arbovirus Threat, N. Engl. J. Med. 374 (2016) 601-604. autochthonous transmission of Zika virus in Brazil., Mem. Inst. Oswaldo Cruz. 110 (2015) 569-572. doi:10.1590/0074-02760150192.

[4] G.S. Campos, A.C. Bandeira, S.I. Sardi, Zika virus outbreak, Bahia, Brazil, Emerg. Infect. Dis. 21 (2015) 1885-1886. doi:10.32301/eid2110.150847. 
D. Musso, E.J. Nilles, V.M. Cao-Lormeau, Rapid spread of emerging Zika virus in the Pacific area, Clin. Microbiol. Infect. 20 (2014) O595-O596. doi:10.1111/1469-0691.12707.

[7] S. Ekins, J. Liebler, B.J. Neves, W.G. Lewis, M. Coffee, R. Bienstock, C. Southan, C.H. Andrade, Illustrating and homology modeling the proteins of the Zika virus., F1000Research. 5 (2016) 1-20. doi:10.12688/f1000research.8213.2.

[8] M. Oglesbee, S. Niewiesk, Measles virus neurovirulence and host immunity., Future Virol. 6 (2011) 85-99. doi:10.2217/fvl.10.70.

[9] J. Mlakar, M. Korva, N. Tul, M. Popović, M. Poljšak-Prijatelj, J. Mraz, M. Kolenc, K. Resman Rus, T. Vesnaver Vipotnik, V. Fabjan Vodušek, A. Vizjak, J. Pižem, M. Petrovec, T. Avšič Županc, Zika Virus Associated with Microcephaly., N. Engl. J. Med. 374 (2016) 951-8. doi:10.1056/NEJMoa1600651.

[10] P. Gérardin, V.-M. Cao-Lormeau, D. Musso, P. Desprès, M. Besnard, Zika rash and increased risk of congenital brain abnormalities, Lancet. 389 (2017) 151-152. doi:10.1016/S0140-6736(17)30014-4.

[11] M.A. Johansson, L. Mier-y-Teran-Romero, J. Reefhuis, S.M. Gilboa, S.L. Hills, Zika and the Risk of Microcephaly, N. Engl. J. Med. 375 (2016) 1-4. doi:10.1056/NEJMp1002530.

[12] T. dos Santos, A. Rodriguez, M. Almiron, A. Sanhueza, P. Ramon, W.K. de Oliveira, G.E. Coelho, R. Badaro, J. Cortez, M. Ospina, R. Pimentel, R. Masis, F. Hernandez, B. Lara, R. Montoya, B. Jubithana, A. Melchor, A. Alvarez, S. Aldighieri, C. Dye, M.A. Espinal, Zika Virus and the Guillain - Barré Syndrome — Case Series from Seven Countries, N. Engl. J. Med. 375 (2016) 1598-1601. doi:10.1056/NEJMc1609015.

[13] G. Carteaux, M. Marquart, A. Bedet, D. Contou, P. Brugieres, S. Fourati, L. Cleret de Langavant, T. de Broucker, C. Brun-Buisson, I. Leparc-Goffart, A.M. Dessap, Zika Virus Associated with Meningoencephalitis, N. Engl. J. Med. 374 (2016) 1592-1595. doi:10.1056/NEJMc1600179.

[14] R. Uraki, J. Hwang, K.A. Jurado, S. Householder, L.J. Yockey, A.K. Hastings, R.J. Homer, A. Iwasaki, E. Fikrig, Zika virus causes testicular atrophy, Sci. Adv. 3 (2017) e1602899. doi:10.1126/sciadv.1602899.

[15] E. D’Ortenzio, S. Matheron, X. de Lamballerie, B. Hubert, G. Piorkowski, M. Maquart, D. Descamps, F. Damond, Y. Yazdanpanah, I. Leparc-Goffart, Evidence of Sexual Transmission of Zika Virus, N. Engl. J. 
B. de Chassey, L. Meyniel-Schicklin, J. Vonderscher, P. André, V. Lotteau, Virus-host interactomics: new insights and opportunities for antiviral drug discovery., Genome Med. 6 (2014) 115. doi:10.1186/s13073-0140115-1.

J.A. Esté, A. Telenti, HIV entry inhibitors, Lancet. 370 (2007) 81-88. doi:10.1016/S0140-6736(07)61052-6.

[18] N. London, B. Raveh, O. Schueler-Furman, Druggable protein-protein interactions - from hot spots to hot segments, Curr. Opin. Chem. Biol. 17 (2013) 952-959. doi:10.1016/j.cbpa.2013.10.011.

[19] N. Schormann, C.I. Sommers, M.N. Prichard, K.A. Keith, J.W. Noah, M. Nuth, R.P. Ricciardi, D. Chattopadhyay, Identification of protein-protein interaction inhibitors targeting vaccinia virus processivity factor for development of antiviral agents, Antimicrob. Agents Chemother. 55 (2011) 5054-5062. doi:10.1128/AAC.00278-11.

E. Yung, M. Sorin, a Pal, E. Craig, a Morozov, O. Delattre, J. Kappes, D. Ott, G. V Kalpana, Inhibition of HIV-1 virion production by a transdominant mutant of integrase interactor 1., Nat. Med. 7 (2001) 920-6. doi:10.1038/90959.

[21] Y. Park, Critical assessment of sequence-based protein-protein interaction prediction methods that do not require homologous protein sequences., BMC Bioinformatics. 10 (2009) 419. doi:10.1186/1471-2105-10-419.

[22] S. Pitre, F. Dehne, A. Chan, J. Cheetham, A. Duong, A. Emili, M. Gebbia, J. Greenblatt, M. Jessulat, N. Krogan, X. Luo, A. Golshani, PIPE: a protein-protein interaction prediction engine based on the re-occurring short polypeptide sequences between known interacting protein pairs., BMC Bioinformatics. 7 (2006) 365. doi:10.1186/1471-2105-7-365. 
[25] F. Eid, M. Elhefnawi, L.S. Heath, Sequence analysis DeNovo: virus-host sequence-based protein - protein interaction prediction, Bioinformatics. 32 (2016) 1144-1150. doi:10.1093/bioinformatics/btv737.

[26] A. Calderone, L. Licata, G. Cesareni, VirusMentha: A new resource for virus-host protein interactions, Nucleic Acids Res. 43 (2015) D588-D592. doi:10.1093/nar/gku830.

[27] A. Schoenrock, F. Dehne, J.R. Green, A. Golshani, S. Pitre, MP-PIPE: a massively parallel protein-protein interaction prediction engine, Proc. Int. Conf. Supercomput. (2011) 327-337. doi:10.1145/1995896.1995946.

[28] A. Amos-Binks, C. Patulea, S. Pitre, A. Schoenrock, Y. Gui, J.R. Green, A. Golshani, F. Dehne, Binding site prediction for protein-protein interactions and novel motif discovery using re-occurring polypeptide sequences., BMC Bioinformatics. 12 (2011) 225. doi:10.1186/1471-2105-12-225.

[29] D.E. Schmechel, M.W. Brightman, P.J. Marangos, Neurons switch from non-neuronal enolase to neuronspecific enolase during differentiation, Brain Res. 190 (1980) 195-214. doi:10.1016/0006-8993(80)91169-5.

[30] P.S. Eriksson, E. Perfilieva, T. Bjork-Eriksson, A.-M. Alborn, C. Nordborg, D.A. Peterson, F.H. Gage, Neurogenesis in the adult human hippocampus, Nat. Med. 4 (1998) 1313-1317.

[31] E. Gould, A.J. Reeves, M. Fallah, P. Tanapat, C.G. Gross, E. Fuchs, Hippocampal neurogenesis in adult Old World primates, PNAS. 96 (1999) 5263-5267.

[32] G.P. Comi, F. Fortunato, S. Lucchiari, A. Bordoni, A. Prelle, S. Jann, A. Keller, P. Ciscato, S. Galbiati, L. Glycolysis, Ann. Neurol. 50 (2001) 202-207. doi:10.1002/ana.1095.

[33] M. Henneke, S. Diekmann, A. Ohlenbusch, J. Kaiser, V. Engelbrecht, A. Kohlschütter, R. Krätzner, M.

Madruga-Garrido, M. Mayer, L. Opitz, D. Rodriguez, F. Rüschendorf, J. Schumacher, H. Thiele, S. Thoms, R. Steinfeld, P. Nürnberg, J. Gärtner, RNASET2-deficient cystic leukoencephalopathy resembles congenital cytomegalovirus brain infection., Nat. Genet. 41 (2009) 773-775. doi:10.1038/ng.398. 
[35] D. Tonduti, S. Orcesi, E.M. Jenkinson, I. Dorboz, F. Renaldo, C. Panteghini, G.I. Rice, M. Henneke, J.H. Livingston, M. Elmaleh, L. Burglen, M.A.A.P. Willemsen, L. Chiapparini, B. Garavaglia, D. Rodriguez, O. Boespflug-Tanguy, I. Moroni, Y.J. Crow, Clinical, radiological and possible pathological overlap of cystic leukoencephalopathy without megalencephaly and Aicardi-Goutieres syndrome, Eur. J. Paediatr. Neurol. 20 (2016) 604-610. doi:10.1016/j.ejpn.2016.03.009.

[36] N. Haud, F. Kara, S. Diekmann, M. Henneke, J.R. Willer, M.S. Hillwig, R.G. Gregg, G.C. Macintosh, J. Gärtner, A. Alia, A.F.L. Hurlstone, rnaset2 mutant zebrafish model familial cystic leukoencephalopathy and reveal a role for RNase T2 in degrading ribosomal RNA., Proc. Natl. Acad. Sci. U. S. A. 108 (2010) 10991103. doi:10.1073/pnas.1009811107.

[37] K. Tokuhiro, Y. Satouh, K. Nozawa, A. Isotani, Y. Fujihara, Calreticulin is required for development of the cumulus oocyte complex and female fertility, Sci. Rep. 5 (2015) 1-10. doi:10.1038/srep14254.

[38] S. Irie, J. Nakamura, Y. Miyagawa, A. Tsujimura, H. Okuda, K. Yamamoto, S. Fukuhara, I. Yoshioka, K. Hiroshi, Y. Matsuoka, T. Takao, N. Nonomura, M. Ikawa, K. Tokuhiro, M. Okabe, T. Shibata, K. Fujimoto, M. Wada, H. Tanaka, Primary Screening of Single Nucleotide Polymorphisms in Human Calreticulin 3 ( CALR3 ), Open Androl. J. 3 (2011) 30-35.

[39] M.D. Dun, R.J. Aitken, B. Nixon, The role of molecular chaperones in spermatogenesis and the post-testicular maturation of mammalian spermatozoa, Hum. Reprod. Update. 0 (2012) 1-16. doi:10.1093/humupd/dms009.

[40] M. Novak, M.K. Leonard, X.H. Yang, A. Korluru, A.M. Belkin, D.M. Kaetzel, Metastasis Suppressor NME1 Regulated Melanoma Cell Morphology, Self-Adhesion and Motility via Induction of Fibronectin Expression, Exp. Dermatol. 24 (2015) 455-461. doi:10.1111/exd.12697.Metastasis.

[41] H. Bauer, S. Schindler, Y. Charron, J. Willert, B. Kusecek, B.G. Herrmann, The nucleoside diphosphate kinase gene nme3 acts as quantitative trait locus promoting non-mendelian inheritance, PLoS Genet. 8 (2012) 1-9. doi:10.1371/journal.pgen.1002567.

[42] H. Nian, C. Fan, S. Liao, Y. Shi, K. Zhang, Y. Liu, C. Han, RNF151, a testis-specific RING finger protein, interacts with dysbindin, Arch. Biochem. Biophys. 465 (2007) 157-163. doi:10.1016/j.abb.2007.05.013. 
[43] S. Shoji-Kawata, Q. Zhong, M. Kameoka, Y. Iwabu, S. Sapsutthipas, R.B. Luftig, K. Ikuta, The RING finger ubiquitin ligase RNF125/TRAC-1 down-modulates HIV-1 replication in primary human peripheral blood mononuclear cells, Virology. 368 (2007) 191-204. doi:10.1016/j.virol.2007.06.028.

[44] L. Liu, D. Feng, G. Chen, M. Chen, Q. Zheng, P. Song, Q. Ma, C. Zhu, R. Wang, W. Qi, L. Huang, P. Xue, B. Li, X. Wang, H. Jin, J. Wang, F. Yang, P. Liu, Y. Zhu, S. Sui, Q. Chen, Q. Chen, Mitochondrial outermembrane protein FUNDC1 mediates hypoxia-induced mitophagy in mammalian cells, Nat. Cell Biol. 14 (2012). doi:10.1038/ncb2422.

[45] W. Hu, J.J. Kavanagh, Anticancer therapy targeting the apoptotic pathway., Lancet Oncol. 4 (2003) 721-9. doi:10.1016/S1470-2045(03)01277-4.

[46] T. Kalkan, Y. Iwasaki, C.Y. Park, G.H. Thomsen, Tumor Necrosis Factor-Receptor - associated Factor-4 Is a Positive Regulator of Transforming Growth Factor- B Signaling That Affects Neural Crest Formation, Mol. Biol. Cell. 20 (2009) 3436-3450. doi:10.1091/mbc.E08.

[47] M. Van Gele, P. Dynoodt, J. Lambert, Griscelli syndrome: A model system to study vesicular trafficking, Pigment Cell Melanoma Res. 22 (2009) 268-282. doi:10.1111/j.1755-148X.2009.00558.x.

[48] A. Onishi, G. Peng, C. Hsu, U. Alexis, S. Chen, S. Blackshaw, Pias3-dependent SUMOylation directs rod photoreceptor development, Neuron. 61 (2010) 234-246. doi:10.1016/j.neuron.2008.12.006.Pias3-dependent.

[49] K. Song, J. Backs, J. McAnally, X. Qi, R.D. Gerard, J.A. Richardson, J.A. Hill, R. Bassel-Duby, E.N. Olson, The Transcriptional Coactivator CAMTA2 Stimulates Cardiac Growth by Opposing Class II Histone Deacetylases, Cell. 125 (2006) 453-466. doi:10.1016/j.cell.2006.02.048.

[50] M. Fukasaka, D. Ori, T. Kawagoe, S. Uematsu, K. Maruyama, T. Okazaki, T. Satoh, T. Kozaki, T. Imamura, M. Takashi, S. Takashi, S. Akira, O. Takeuchi, E. Alerts, Critical Role of AZI2 in GM-CSF - Induced Dendritic Cell Differentiation, J. Immunol. 190 (2013) 5702-5711. doi:10.4049/jimmunol.1203155.

[51] F. Quintero-Rivera, Q.J. Xi, K.M. Keppler-Noreuil, J.H. Lee, A.W. Higgins, R.M. Anchan, A.E. Roberts, I.S. Seong, X. Fan, K. Lage, L.Y. Lu, J. Tao, X. Hu, R. Berezney, B.D. Gelb, A. Kamp, I.P. Moskowitz, R. V. Lacro, W. Lu, C.C. Morton, J.F. Gusella, R.L. Maas, MATR3 disruption in human and mouse associated with 
371

372

373

374

375

376

377

378

379

380

381

382

383

384

385

386

387

388

389

390

391

392

393

394

395

bicuspid aortic valve, aortic coarctation and patent ductus arteriosus, Hum. Mol. Genet. 24 (2015) 2375-2389. doi:10.1093/hmg/ddv004.

[52] M. Marjanović, C. Sánchez-Huertas, B. Terré, R. Gómez, J.F. Scheel, S. Pacheco, P.A. Knobel, A. MartínezMarchal, S. Aivio, L. Palenzuela, U. Wolfrum, P.J. McKinnon, J.A. Suja, I. Roig, V. Costanzo, J. Lüders, T.H. Stracker, CEP63 deficiency promotes p53-dependent microcephaly and reveals a role for the centrosome in meiotic recombination., Nat. Commun. 6 (2015) 7676. doi:10.1038/ncomms8676.

[53] D.A. Calderwood, The Rap1-RIAM pathway prefers B 2 integrins, Immunobiology. 126 (2015) 2658-2660. doi:10.1182/blood-2015-09-668962.

[54] F. Dahdouh, H. Anthoni, I. Tapia-pa, M. Peyrard-Janvid, G. Schulte-ko, A. Warnke, H. Remschmidt, A. Ziegler, J. Kere, B. Muller-Myhsok, M.M. Nothen, J. Schumacher, M. Zucchelli, Further evidence for DYX1C1 as a susceptibility factor for dyslexia, Psychiatr. Genet. 19 (2007) 59-63. doi:10.1097/YPG.0b013e32832080e1.

[55] R. Smith, P. Klein, Y. Koc-Schmitz, H.J. Waldvogel, R.L.M. Faull, P. Brundin, M. Plomann, J.Y. Li, Loss of SNAP-25 and rabphilin 3a in sensory-motor cortex in Huntington's disease, J. Neurochem. 103 (2007) 115123. doi:10.1111/j.1471-4159.2007.04703.x.

[56] D. Morales, R. Hechavarria, V. Wojna, S.F. Acevedo, YWHAE/14-3-3e: a A potential novel genetic risk factor and CSF biomarker for HIV neurocognitive impairment, J. Neurovirol. 19 (2013) 471-478. doi:10.1007/s13365-013-0200-z.

[57] I. Hamza, J.D. Gitlin, Copper chaperones for cytochrome c oxidase and human disease, J. Bioenerg. Biomembr. 34 (2002) 381-388. doi:10.1023/A:1021254104012.

[58] S.H. Hsu, H.M. Hsieh-Li, H. Li, Dysfunctional spermatogenesis in transgenic mice overexpressing bHLHZip transcription factor, Spz1, Exp. Cell Res. 294 (2004) 185-198. doi:10.1016/j.yexcr.2003.10.029.

[59] Y. Hu, Z. Zhou, X. Huang, M.I.N. Xu, L.I. Lu, Z. Xu, J. Li, J. Sha, Expression of a novel DnaJA1 alternative splicing in human testis and sperm, Int. J. Androl. 27 (2004) 343-349.

[60] P.S. Eriksson, E. Perfilieva, T. Björk-Eriksson, a M. Alborn, C. Nordborg, D. a Peterson, F.H. Gage, 
[61] S.A. Rasmussen, D.J. Jamieson, M.A. Honein, L.R. Petersen, Zika Virus and Birth Defects — Reviewing the Evidence for Causality, N. Engl. J. Med. 274 (2016) 1981-1987. doi:10.1056/NEJMsr1604338.

[62] L. Vidalino, L. Monti, A. Haase, A. Moro, F. Acquati, R. Taramelli, P. Macchi, Intracellular trafficking of RNASET2, a novel component of P-bodies, Biol. Cell. 104 (2012) 13-21. doi:10.1111/boc.201100092.

[63] N. Haud, F. Kara, S. Diekmann, M. Henneke, J.R. Willer, M.S. Hillwig, R.G. Gregg, G.C. MacIntosh, J. Gärtner, A. Alia, A.F.L. Hurlstone, rnaset2 mutant zebra fish model familial cystic leukoencephalopathy and reveal a role for RNase T2 in degrading ribosomal RNA, PNAS. (2010) 1-5. doi:10.1073/pnas.1009811107.

[64] P.T. Dolan, C. Zhang, S. Khadka, V. Arumugaswami, A.D. Vangeloff, N.S. Heaton, S. Sahasrabudhe, G. interactions., Mol. Biosyst. 9 (2013) 3199-209. doi:10.1039/c3mb70343f.

J. Wu, A.K. Bera, R.J. Kuhn, J.L. Smith, Structure of the Flavivirus Helicase: Implications for Catalytic Activity, Protein Interactions, and Proteolytic Processing, J. Virol. 79 (2005) 10268-10277. doi:10.1128/JVI.79.16.10268.

P. Campomenosi, S. Salis, C. Lindqvist, D. Mariani, T. Nordström, F. Acquati, R. Taramelli, Characterization of RNASET2, the first human member of the Rh/T2/S family of glycoproteins, Arch. Biochem. Biophys. 449 (2006) 17-26. doi:10.1016/j.abb.2006.02.022. 
cells, Biomed Res. Int. 2013 (2013) 1-11. doi:10.1155/2013/875958.

422 [70] T.J. Nowakowski, A.A. Pollen, E. Di Lullo, C. Sandoval-Espinosa, M. Bershteyn, A.R. Kriegstein, Expression 423 analysis highlights AXL as a candidate zika virus entry receptor in neural stem cells, Cell Stem Cell. 18 (2016) 591-596. doi:10.1016/j.stem.2016.03.012.

425

[71] R.H. Arch, R.W. Gedrich, C.B. Thompson, Tumor necrosis factor receptor-associated factors (TRAFs) - a family of adaptor that regulates life and death, Genes Dev. 12 (1998) 2821. doi:10.1101/gad.12.18.2821.

S. Khadka, A.D. Vangeloff, C. Zhang, P. Siddavatam, N.S. Heaton, L. Wang, R. Sengupta, S. Sahasrabudhe, and human proteins, Mol. Cell. Proteomics. 10 (2011) M111.012187. doi:10.1074/mcp.M111.012187. 


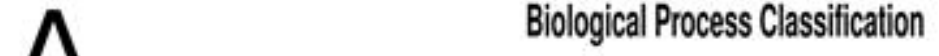

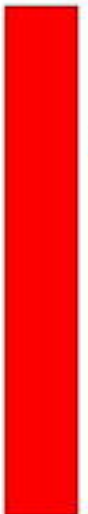

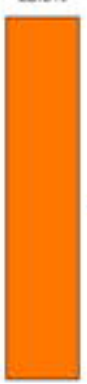

10.64

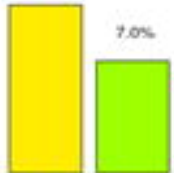

$6.0 \%$

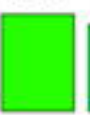

$5.4 \%$
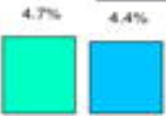

Metabolic Process

Cellular Process

Biological Regulation

D] Derebopmental Process.

口 Aosconse to Stimulus

口 Localiusation

[ immune System Precess

$\square$ Celular Component Organiration of Biogenesis

- Muticelular Orgarismal Process

- Apeptotic Process

D Biological Adrewion

口 Reproduction

a Cown

\section{$\mathrm{B}$}

\section{Cellular Component Classification}
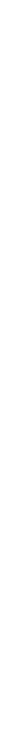

\section{Molecular Function Classification}


Zika Virus Particle

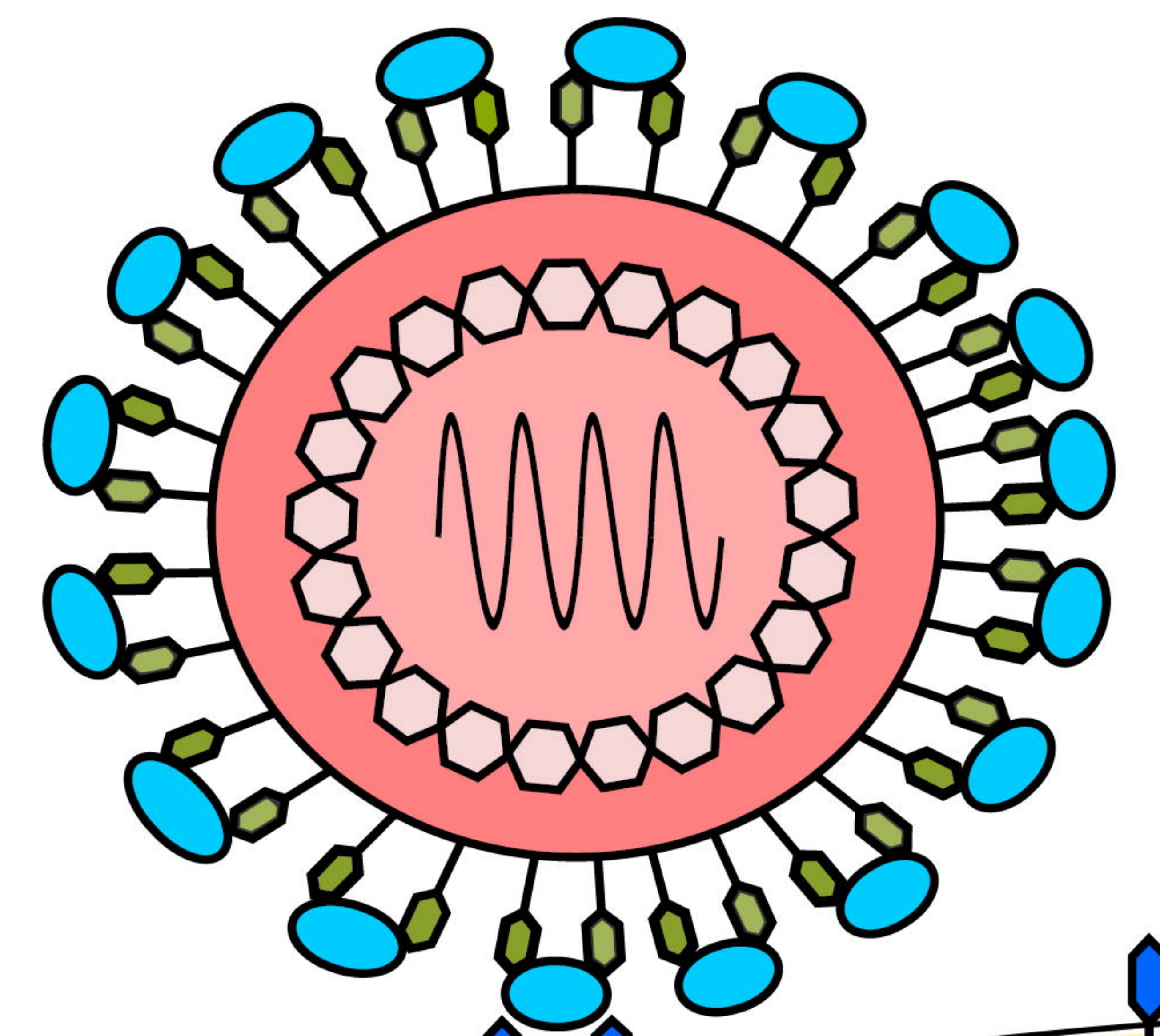

Zika Virus

Proteins
Human

Proteins

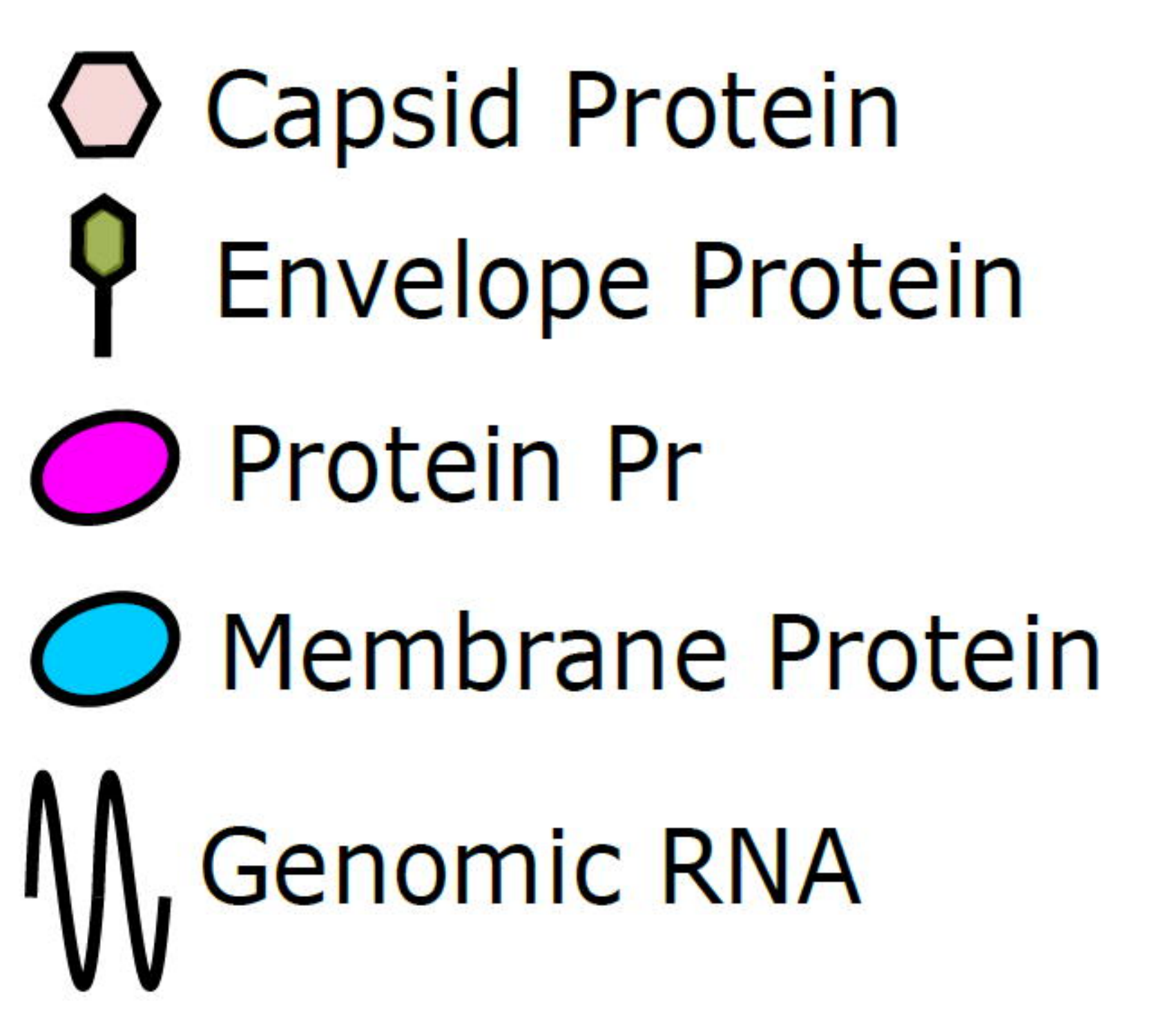

NS1

NS2A

NS2B

NS3

NS4A

NS4B

NS5

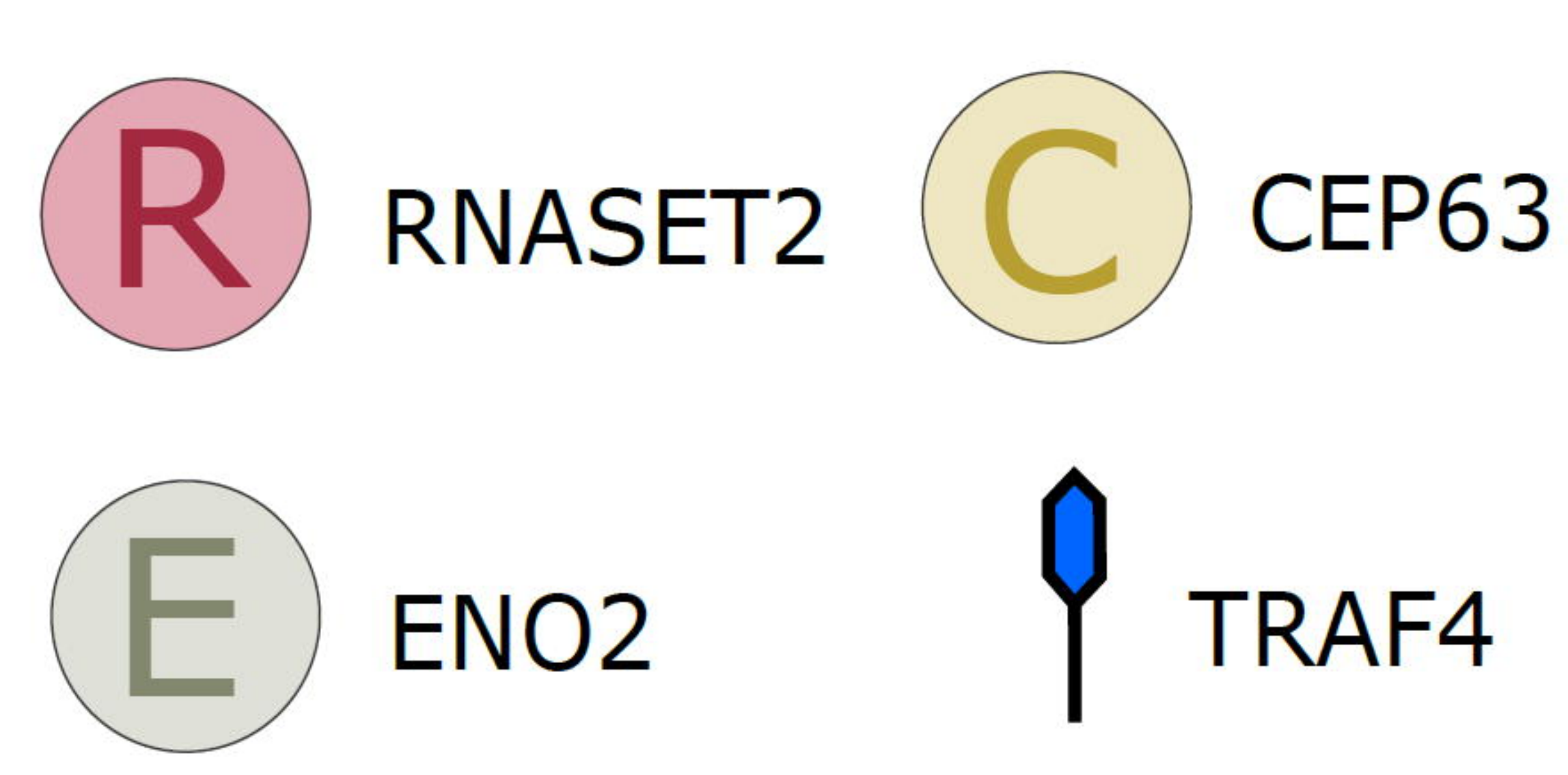

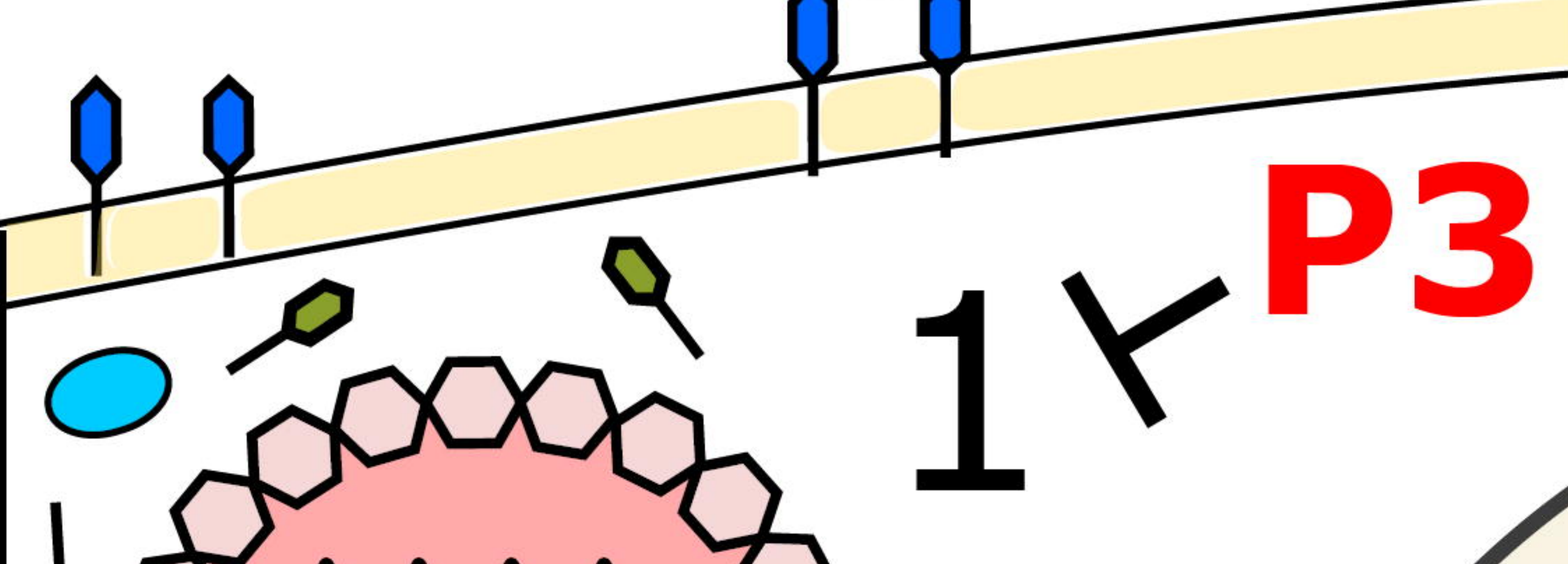
-

2
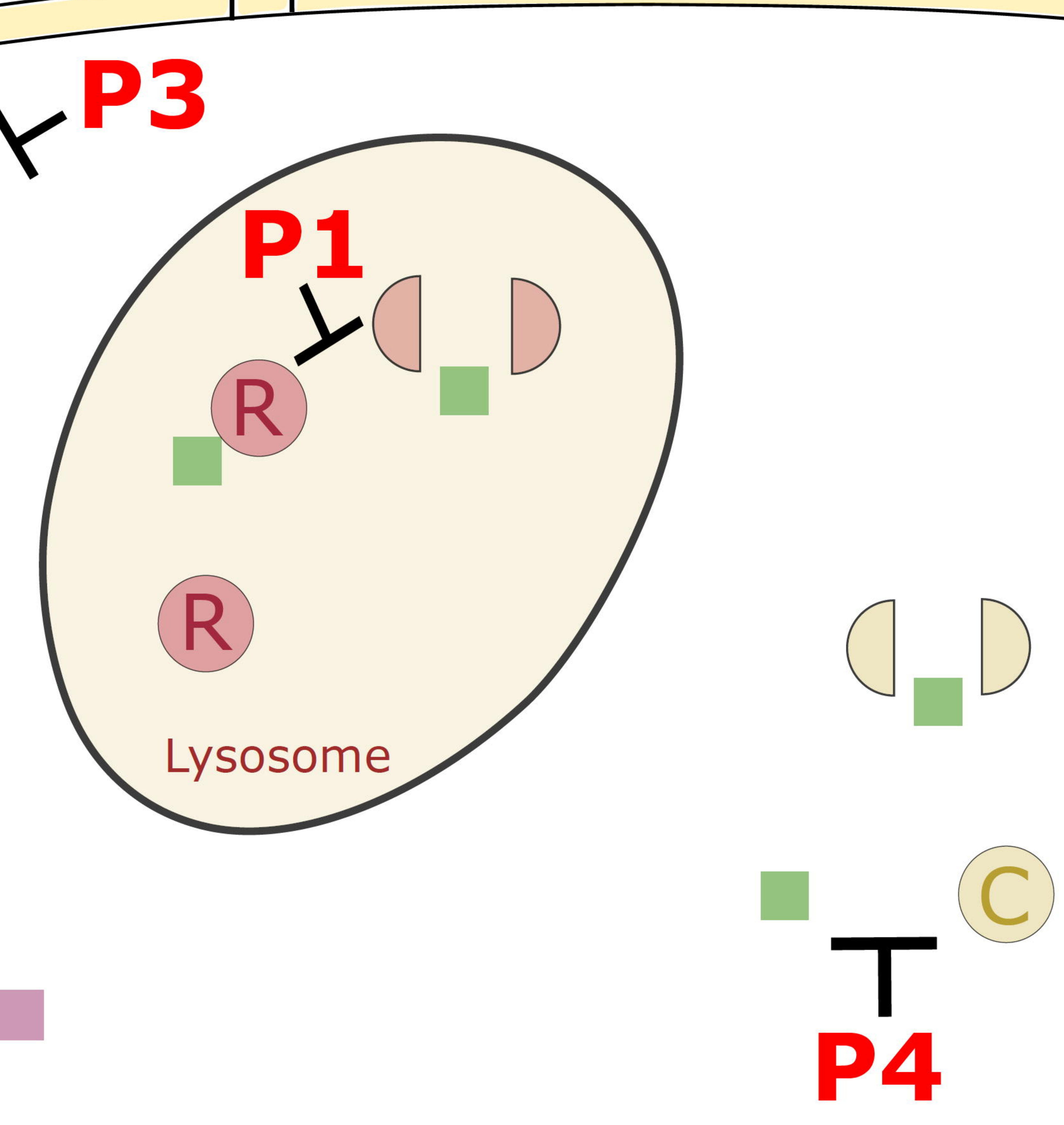

P3 ‘ 5
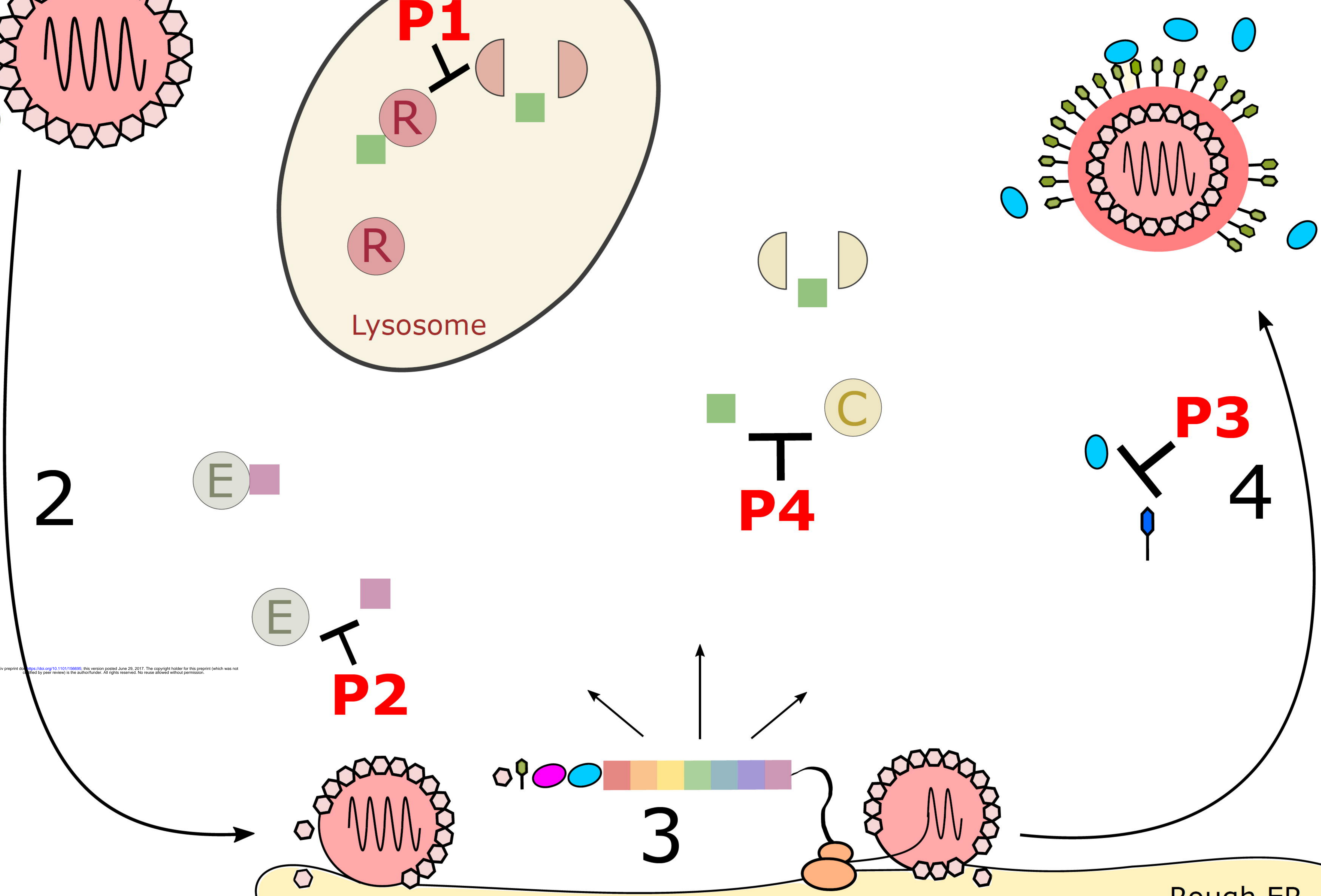

Cytosol
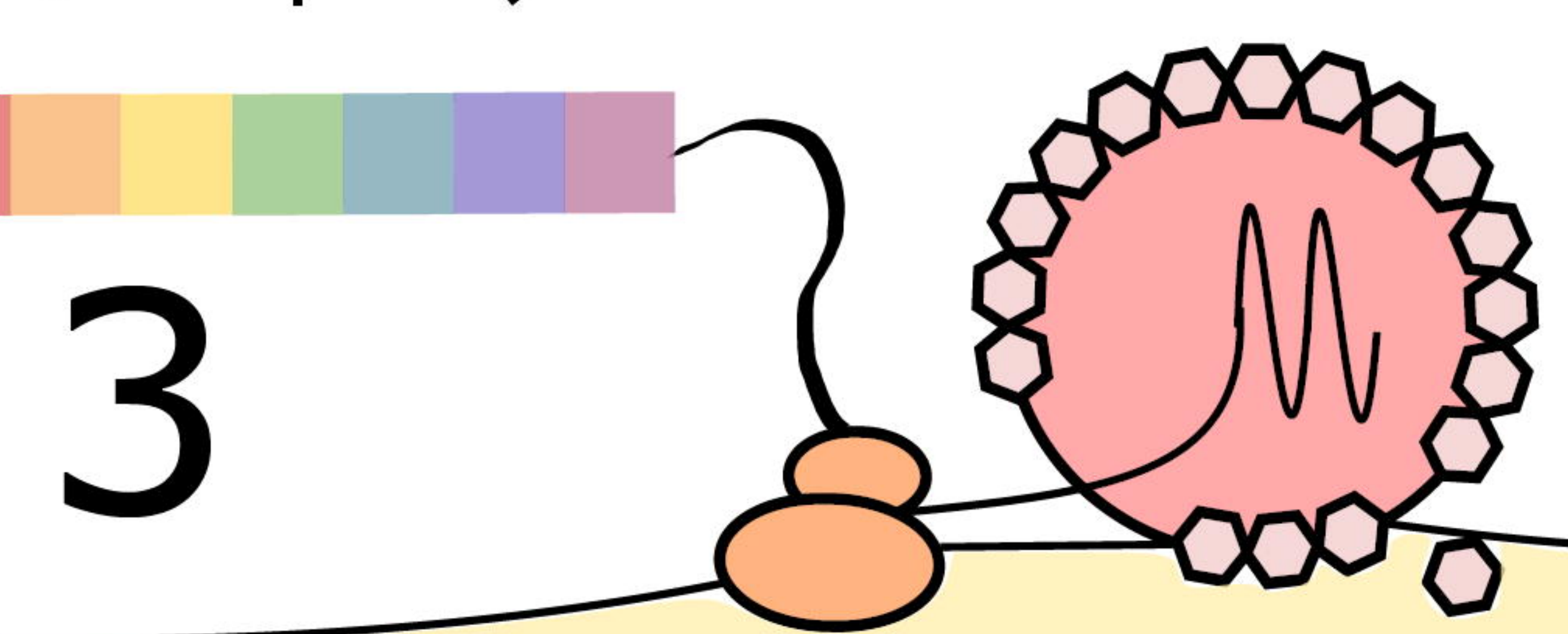

Rough ER 